\title{
MORPHOFUNCTIONAL STATUS OF CARDIO-VASCULAR SYSTEM OF RATS WITH ARTERIAL HYPERTENSION
}

DOI: 10.36740/WLek202002128

\author{
Svetlana M. Chuhray ${ }^{1}$, Viktoria E. Lavrynenko ${ }^{2}$, Rostyslav F. Kaminsky ${ }^{1}$, Iryna V. Dzevulska' ${ }^{1}$, Oleksandr V. Malikov' ${ }^{1}$ \\ Ruzhena M. Matkivska' ${ }^{1}$, Larysa B. Shobat ${ }^{1}$, Oleksandr I. Kovalchuk ${ }^{1,2}$, Liudmyla M. Sokurenko ${ }^{1,2}$ \\ 'BOGOMOLETS NATIONAL MEDICAL UNIVERSITY, KYIV, UKRAINE \\ ${ }^{2}$ TARAS SHEVCHENKO NATIONAL UNIVERSITY OF KYIV, KYIV, UKRAINE
}

\begin{abstract}
The aim: Was to clarify the general patterns of structural changes in the left ventricular myocardial capillaries in rats with spontaneous arterial hypertension. Materials and methods: Experiments were conducted on 50 ISIAH (inherited stress-induced arterial hypertension) line rats with arterial hypertension: juvenile young (45-day) and sexually mature (100-day) rats, as well as intact animals of the corresponding age. While extracted from the experiment rats of all experimental groups had their arterial pressure measured using a plethysmograph. Electron microscopic examination of the left ventricular myocardium and morphometric study of volumetric and quantitative densities, cross-section area, and form factor of micropinocytotic vesicles were conducted.

Results: In sexually mature rats with arterial hypertension, a high level of pressure is maintained. In 45-day-old rats with arterial hypertension in endothelial cells of myocardial blood capillaries there is a hyperactivation of biosynthetic processes (euchromatic nucleus, large-sized mitochondria, ER canals, Golgi complex), which may be a manifestation of reactive processes in response to a non-stable increase in arterial pressure. In the 100-day rats with arterial hypertension, the mosaic of the ultrastructure of the myocardium blood vessels is preserved, but destructively-dystrophic changes become more expressive and involve not only the organelles but also the integrity of the endothelial cell itself. Destructively-dystrophic processes in rat capillaries are accompanied by compensatory and adaptive ones. This is manifested by activation of the transport of substances, both transendothelial and paracellular, and quantitative density of micropinocytotic vesicles increases statistically significantly.

Conclusions: In myocardial capillaries of young (45-day) arterial hypertension rats, compensatory and adaptive changes are manifested by activation of biosynthetic processes in endothelial cells following a slight increase in micropinocytotic vesicles quantitative density and signs of destructive-dystrophic processes (minor edema and lysis of endothelial cell cytoplasm).

In sexually mature (100-day) arterial hypertension rats in the blood capillaries of the myocardium, the destructive-degenerative changes increase is accompanied by preservation of signs of compensatory processes. Reducing the number of capillaries is offset by an increase in the number of micropinocytotic vesicles.
\end{abstract}

KEY WORDS: myocardium, blood capillaries, rat, hypertension, electron microscopy

Wiad Lek. 2020;73(2):355-359

\section{INTRODUCTION}

Arterial hypertension is one of the most common cardiovascular disease syndromes. The total frequency of various forms of arterial hypertension $(\mathrm{AH})$ is about $30 \%$ of the adult population of Ukraine. As a rule, arterial hypertension develops gradually and proceeds chronically, has its age characteristics. Over the past decades, arterial hypertension has significantly "youthened" and, according to many researchers, begins to be formed notably in childhood.

In research of the structural fundamentals of arterial hypertension, the main attention was paid to the study of cardiomyocytes and major blood vessels [1-2] At the same time interesting, from our point of view, is the state of small blood vessels, because the capillary circulation provides the main function of the microcirculatory bloodstream - the exchange of substances between blood and tissues. Thus, the state of blood microcirculation can serve as the arbiter of the well-being of systemic hemodynamics.

\section{THE AIM}

The aim of the study was to clarify the general patterns of structural changes in the left ventricular myocardial capillaries in rats with spontaneous arterial.

\section{MATERIALS AND METHODS}

Experiments were performed on 50 white rats, which were under standard vivarium conditions of the Bogomolets National Medical University. The juvenile (45-day), sexually-grown (100-day) and old (240-day) ISIAH (inherited stress-induced arterial hypertension) line rats with arterial hypertension were studied. These animals are a convenient research material, because all signs and symptoms inherent in human hypertension are reproduced on this model of rats [3]. Control was provided by intact rats of the Wistar line of the same age. Experiments with animals were carried out in accordance with the Law of Ukraine "On protection of animals from cruelty" (2006), "General ethical princi- 
Table 1. Changes of arterial pressure figures

\begin{tabular}{ccc}
\hline \multirow{2}{*}{ Groups of animals } & \multicolumn{2}{c}{ Arterial pressure, $\mathbf{~ m m ~ H g}$} \\
\cline { 2 - 3 } & $\mathbf{4 5}$ days & $\mathbf{1 0 0}$ days \\
\hline Control & $98,7 \pm 6,1$ & $109,4 \pm 5,3$ \\
\hline $\mathrm{AH}$ & $125,2 \pm 5,9^{*}$ & $145,3 \pm 5,1^{*}$ \\
\hline
\end{tabular}

Note: ${ }^{*}-p<0,05$ in comparison with the data of the Control;

${ }^{* *}-p<0,05$ in comparison with the data of the other term group.

Table 2. The morphometric indexes of micropinocytotic vesicles in endothelial cells of myocardial circulatory capillaries

\begin{tabular}{|c|c|c|c|c|c|}
\hline $\begin{array}{l}\text { Age of } \\
\text { animals }\end{array}$ & Groups & $\begin{array}{c}\text { Volumetric density, } \\
\%\end{array}$ & $\begin{array}{c}\text { Quantitative density, } \\
\qquad 1 / \mu \mathrm{m}^{3}\end{array}$ & $\begin{array}{c}\text { Average area, } \\
10^{-2} \mu \mathrm{m}^{2}\end{array}$ & Form factor \\
\hline \multirow{2}{*}{45 days } & Control & $18,09 \pm 1,04$ & $282,7 \pm 15,9$ & $0,57 \pm 0,01$ & $0,84 \pm 0,05$ \\
\hline & $\mathrm{AH}$ & $17,20 \pm 1,07$ & $306,8 \pm 13,3^{*}$ & $0,56 \pm 0,01$ & $0,83 \pm 0,00$ \\
\hline \multirow{2}{*}{100 days } & Control & $21,95 \pm 0,85$ & $332,5 \pm 18,6$ & $0,57 \pm 0,01$ & $0,85 \pm 0,07$ \\
\hline & $\mathrm{AH}$ & $20,18 \pm 1,14$ & $376,9 \pm 15,2^{* * * *}$ & $0,56 \pm 0,01$ & $0,85 \pm 0,09$ \\
\hline
\end{tabular}

Note: ${ }^{*}-p<0,05$ in comparison with the data of the Control;

$* *-p<0,05$ in comparison with the data of the other term group.

ples of animal experiments", adopted by the First National Congress on Bioethics (Kiev, 2001) and in accordance with the requirements of the "European Convention for the Protection of Vertebrate Animals Used for Experimental and other Scientific Purposes" (Strasbourg, 1985).

Measuring of arterial pressure, morphometric studies, electron microscopic examinations were carried out as in the previous article on the study of cardio-vascular system [4].

While extracted from the experiment, rats of all experimental groups had their arterial pressure measured using a plethysmograph.

Electron microscopic examination of the left ventricular myocardium of experimental rats was conducted. The material was processed in accordance with the generally accepted techniques of electron microscopic examination [5]. Ultra-thin sections were made with ultratome Reihart (Austria) and examined using an electron microscope PEM-125K.

Morphometric studies were carried out on a semi-automatic device for graphic research processing using the program "Organelle". Volumetric and quantitative densities, cross-section area, form factor of micropinocytotic vesicles were studied. Statistical processing was carried out using the Student parametric criterion and the nonparametric Kolmogorov-Smirnov criterion according to the principle of variation statistics.

\section{RESULTS}

Changes in functional parameters in experimental rats

In 45-day-old arterial hypertension rats, arterial pressure exaggerates the pressure of control animals not sharp, but significantly. At 100 days after birth, blood pressure, compared with control animals, is elevated. (Table 1).

Micropinocytotic vesicles in endothelial cells of myocardial blood capillaries
Morphometric analysis of endothelial cells of myocardial circulatory capillaries in 45-day rats with arterial hypertension didn't show statistically significant changes in morphometric indexes of micropinocytotic vesicles, except for the index of quantitative density of micropinocytotic vesicles, which is statistically significantly higher than in the control. Interestingly, from our point of view, there are changes in this indicator in 100 day-old rats with arterial hypertension, which statistically significantly increases in relation to both control and previous term groups. Other indicators that characterize micropinocytosis in blood capillaries, volumetric density, cross-section area and form factor of micropinocytotic vesicles, in 100 day-old rats with arterial hypertension do not differ significantly from similar age-control indicators (Table 2).

Ultrastructure of blood capillaries of myocardium in rats In 45-day-old arterial hypertension rats, myocardial blood capillaries are lined with heteromorphic in ultrastructure endothelial cells. A part of these cells has morphological features of somewhat increased biosynthetic activity: euchromatic nucleus, large size of mitochondria, ER canals, Golgi complex. The number of these organelles is higher compared to 45-day intact animals.

Against the background of active transport processes, which, according to stereological indicators, do not differ from age-related controls (Table 2), there are areas of thinning spread around endothelium up to a thickness of one to two micropinocytotic vesicles. There is lysis and edema of endothelial cells and their organelles, primarily mitochondria. In the myocardium of the rats, there is perivascular edema and accumulation of metabolic products in the interstitium (Fig. 1).

In 100-day rats with arterial hypertension organelle destruction and endothelial cell death are observed in the blood capillaries of the myocardium, the gaps in some inter-endothelial junctions increase. The quantitative density of micropinocytotic vesicles increases in this age group (Fig. 2 ), unlike control and the previous term group (Table 2). 


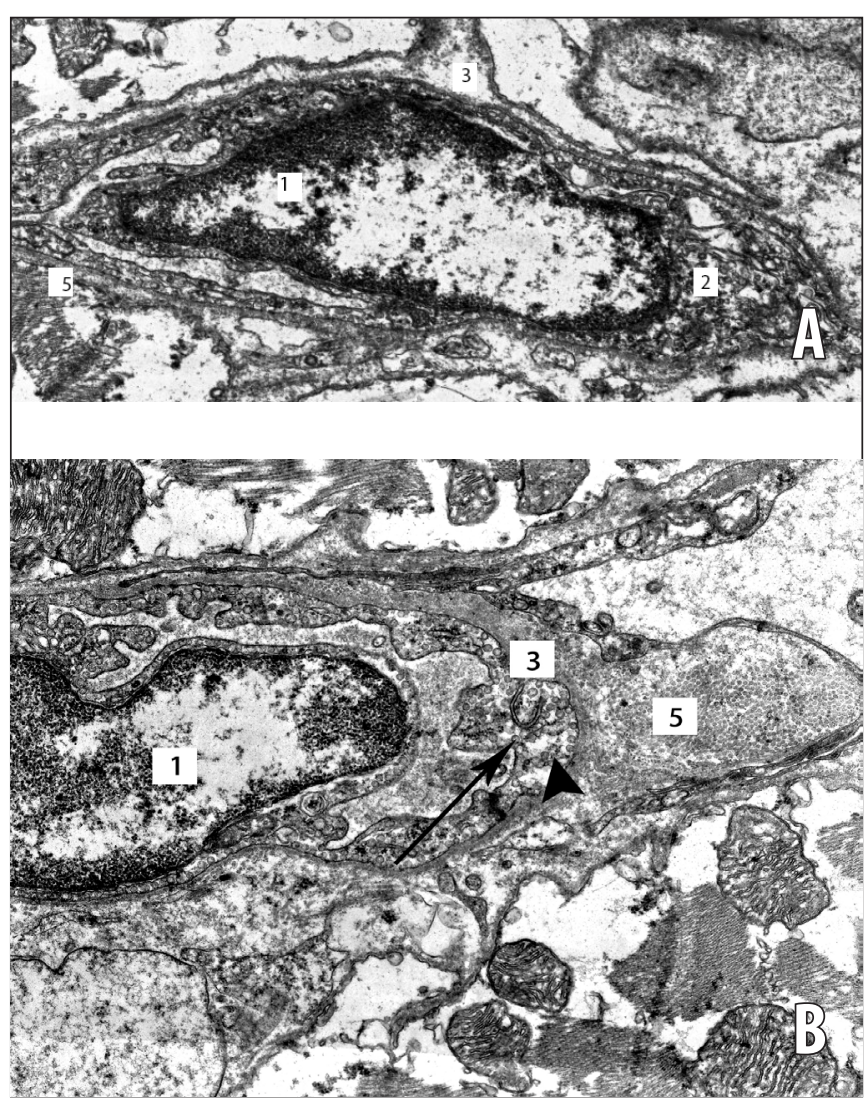

Fig. 1. Blood capillaries of the left ventricular myocardium in 45-day rat with arterial hypertension. Electron microscopic photo. Magnification: A-12000; B -16000: Nucleus (1), mitochondria (2), ER canals (3), micropinocytotic vesicles $(\boldsymbol{\Lambda})$, interendothelial junctions $(\uparrow)$ in endothelial cells, basal lamina (4), collagen fibers (5) in interstitium.

\section{DISCUSSION}

Consequently, in the sexually mature rats with arterial hypertension, a high level of pressure is steadily maintained, for comparison, just about half of the animals with congenital hypothyroidism showed increase of this parameter [6]

In the 45-day arterial hypertension rats in the endothelial cells of the myocardial blood capillaries, hyperactivation of biosynthetic processes occurs (euchromatic nucleus, large in size mitochondria, canals of ER, Golgi complex), which may be a manifestation of reactive processes in response to a non-stable increase in blood pressure. The occurrence of platelet and fine particle aggregates in the lumen of myocardial capillaries is a manifestation of the influence of blood pressure, since it is known that essential arterial hypertension is accompanied by a decrease in the production of prostacyclins and $\mathrm{NO}$ by endothelial cells - they are known to be powerful platelet aggregation inhibitors [7-8]. In addition to the above-described changes, in the myocardium capillaries of rats with arterial hypertension compensatory-adaptive processes are observed: the stereological indices of micropinocytotic vesicles do not differ from age control, the thinning of some areas in endothelial cells is observed. This reduces the way of transport of substances and oxygen and is inherent to the blood capillaries under

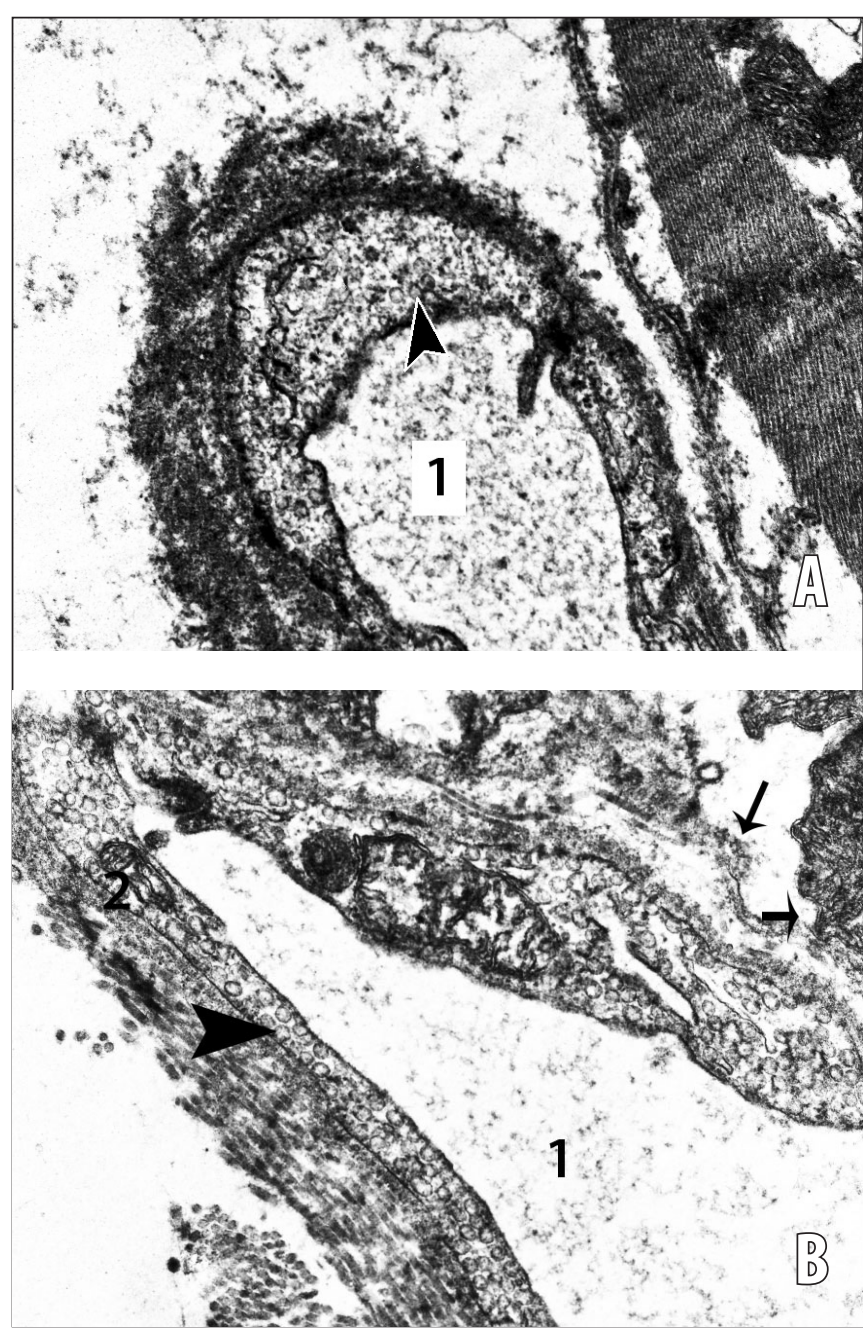

Fig. 2. Blood capillaries of the left ventricle myocardium of 100-day rats with arterial hypertension. Electron microscopic photo. Magnification: A-48000; B-35000. Lumen (1) of blood capillary, mitochondria (2), micropinocytotic vesicles ( $\mathbf{\Lambda}$ ) in endothelial cells, basal lamina (3).

different pathologies. Destructive and dystrophic changes are manifested by lysis and edema of endothelial cells and their organelles, primarily mitochondria. The cytoplasmic edema is, most likely, due to violations of the phospholipid composition of the plasma membrane of endothelial cells, since it is known that arterial hypertension is accompanied by changes in the metabolism of fatty acids that are part of the plasma membranes [9-10]. In addition, increased permeability of endothelial plasma membranes leads to the appearance of perivascular edema and accumulation of metabolic products in the interstitium of myocardium of 45-day arterial hypertension rats, which impairs the metabolism of cardiomyocytes.

In the 100-day arterial hypertension rats, the mosaic of the ultrastructure of the blood vessels in the myocardium is preserved, but destructively-dystrophic changes become more expressive and apply not only to the organelles but also to the integrity of the endothelial cell itself. The death of endothelial cells leads to a decrease in the number of functioning capillaries. Destructively-dystrophic processes in rat 
capillaries are accompanied by compensatory and adaptive ones. This is manifested by the activation of the transport of substances, both transendothelial and paracellular. The increase of microvesiculation processes, which is reflected in the quantitative density of micropinocytotic vesicles in this age group, may be caused by several factors: this is the redistribution in the molecular composition of the plasma membranes as well as the accumulation of calcium ions in the cytoplasm, and the activation of lipid peroxide oxidation processes. All these rearrangements are characteristic for arterial hypertension and can play certain role in the changes in transcytosis, which in this period of observation, nevertheless, are compensatory oriented. Changes in intercellular transport are ultrastructurally manifested by increase of gaps in some inter-endothelial junctions. It is believed that this occurs in those junctions that are mechanically weak, that is, open junctions, due to changes in hemodynamics or osmolarity of the surrounding fluid in case of $\mathrm{Na}^{+} / \mathrm{Ca}^{2+}$ exchange disorder in arterial hypertension rats [11-13].

Consequently, in the development of arterial hypertension, an important role is played by endothelium dysfunction [14-17]. The exchange of substances is in direct dependence on the permeability of blood capillaries. One of its main pathways is transcytosis, the structural expression of which is micropinocytotic vesicles [1]. Phenotypic peculiarity of myocardial blood capillaries is the predominance of processes of micropinocytosis over biosynthetic, that is, the basic structures that are represented in the endothelium of these micro-vessels are micropinocytotic vesicles. The quantitative representation of these structures varies depending on age and pathological state and may be an indicator of both the stages of differentiation and the degree of damage [19].

\section{CONCLUSIONS}

In myocardial capillaries of young (45-day) arterial hypertension rats compensatory-adaptive changes are manifested by activation of biosynthetic processes in endothelial cells, with a slight increase in the micropinocytotic vesicles quantitative density. Signs of destructive-dystrophic processes are edema and lysis of the endothelial cell cytoplasm, which do not become widespread in this period of observation.

In the blood capillaries of the myocardium of sexually mature (100-day) arterial hypertension rats the destructive-degenerative changes increase with the preservation of signs of compensatory processes. Reducing number of capillaries is offset by increase in the number of micropinocytotic vesicles.

\section{REFERENCES}

1. Dzyak G.V., Goncharov 0.S. Application of selective $\beta$-adrenoblocker bisoprolol in the treatment of patients with chronic heart failure. Cardiologist practice. 2006; 4(1):1-5.

2. Dovgan R.S., Stechenko L.0., Zagorodniy M.I., Chekman I.S. Morphofunctional features of the cardiac myocardial ultrastructure of rats with spontaneous arterial hypertension. Visn morphology. 2007; 13(2): 255-260.
3. Antonov Ye.V., Alexandrovich Yu.V., Seryapina A.A., Klimov L.O., Markel A.L. Stress and arterial hypertension: ISIAH rat strain. Vavilovskii Zhurnal Genetiki i Selektsii - Vavilov Journal of Genetics and Breeding. 2015; 19(4): 455-459. DOI 10.18699/VJ15.060

4. Chuhray S.M., Lavrynenko V.E., Kaminsky R.F., Dzevulska I.V., Malikov 0.V., Kovalchuk 0.I., Sokurenko L.M. Morphofunctional status of cardiovascular system of rats with congenital hypotireosis. Wiad Lek. 2019; 72(2): 229-233.

5. Karupu V.Ya. Electron microscopy. K.: Vishcha School, 1984: 208 p.

6. Chuhray S.M., Lavrynenko V.E., Kaminsky R.F., Ustymenko 0.S., Dzevulska I.V., Matkivska R.M, Kovalchuk 0.I., Holubchenko 0., Sokurenko L.M. The influence of drug treatment on cardio-vascular system of the rats with congenital hypothyroidism. Wiad Lek. 2019;71(7):1300-1303.

7. Kuklinska A.M., Mroczko B., Musial W.J., Usowicz-Szarynska M., Sawicki R., Borowska H., Knapp M., Szmitkowski M. Diagnostic biomarkers of essential arterial hypertension: the value of prostacyclin, nitric oxide, oxidized-LDL, and peroxide measurements. Int Heart J. 2009; 50(3):341-351.

8. Versari D., Daghini E., Virdis A., Ghiadoni L., Taddei S. Endotheliumdependent contractions and endothelial dysfunction in human hypertension. Br. J. Pharmacol. 2009; 157(4): 527-536.

9. Kozyreva T.V., Loshakina S.V., Tuzikov F.V. Changes in the composition of blood lipoproteins under the influence of cold effects in normotensive and hypertensive rats. Patol Physiologist Experiment therapy 2006; 1 : 20-22.

10. Kozyreva TV, Loshakina S.V., Tuzikov F.V. Changes in the composition of blood lipoproteins under the influence of cold exposure in normotensive and hypertensive rats. Patol. Fiziol. Experiment. therapy. 2007;13( 2): 255-260.

11. Bhattacharjee A.K., Nagashima T., Kondoh T., Tamaki N. The effects of the $\mathrm{Na}+\mathrm{Ca} 2+$ exchange blocker on osmotic blood-brain barrier. Brain Res. 2001; 900: 157-162.

12. Ueno M. Sakamoto H., Liao Y., Onodora M., Huang C., Miyanak H., Nakagawa T. Blood-brain barrier disruption in the hypothalamus of young adult spontaneously hypertensive rats. Histochem. Cell Biol. 2004; 122: 131-137.

13. Al-Sarraf H. Time Course of Hyperosmolar Opening of the Blood-Brain and Blood-CSF Barriers in Spontaneously Hypertensive Rats. J.Vascular Res. 2007; 44(2): 99-109.

14. Kuzminova N.V., Serkova V.K. The effect of antihypertensive drugs on endothelial dysfunction in patients with hypertension. Ukr. honey. Chasopis. 2008; 2 (64) III/IV: 66-74.

15. Sobolev G.N., Rogoza A.N., Shumilina M.V., BuziashviliYu.I., KarpovYu.A. Endothelial dysfunction in arterial hypertension: vasoprotective effects of b-blockers of a new generation. Cardiology. 2001; 9 (18): 754 -757.

16. Boulanger C.M. Secondary endothelial dysfunction: hypertension and heart failure. Mol. Cell Cardiol. 1999; 31(1): 39-49.

17. Taddei S. Ghiadoni L., Virdis A., Versari D., Salvetti A. Mechanisms of endothelial dysfunction: clinical significance and preventive nonpharmacological therapeutic strategies. Curr. Pharm. Des. 2003; 9: 2385-2402.

18. Karaganov J.L., Mironov V.A., Mironov A.A. Reactivity of the vascular endothelium. Vascular endothelium. Ed. V.V. Kupriyanov, I.I. Bobrik, Ya.L.Karaganova.- Kiev: Health, 1986; 183-199.

19. Stechenko L.O., Zagorodniy M.I., Dovgan R.S., Chekman I.S. Morphofunctional features of the cardiac myocardial ultrastructure of rats with spontaneous arterial hypertension. Visn. morphology 2007; 13(2):255-260. 


\section{Acknowledgements}

The authors would like to thank the employees of the Scientific Research Institute Experimental And Clinical Medicine (Institute of Pathologists Problems) at Bogomolets National Medical University prof. L.O. Stechenko and T.P.Kuftyreva.

\section{ORCID and contributionship:}

Svetlana M. Chuhray - 0000-0001-7431-7375

Viktoria E. Lavrynenko -0000-0002-2570-1271

Rostyslav F. Kaminsky-0000-0001-5744-7581, C,E

Iryna V. Dzevulska - 0000-0002-8043-6626 $6^{E, F}$

Oleksandr V. Malikov - 0000-0002-8113-2974

Ruzhena M. Matkivska - 0000-0002-4082-2899E

Larysa B. Shobat - 0000-0002-8592-520X ${ }^{F}$

Oleksandr I. Kovalchuk - 0000-0002-6311-3518 ${ }^{F}$

Liudmyla M. Sokurenko - 0000-0002-6870-2290

\section{Conflicts of interest:}

Authors declare no conflict of interest.

\section{CORRESPONDING AUTHOR}

Liudmyla M. Sokurenko

Bogomolets National Medical University

Kyiv, Ukraine

e-mail: I-sokurenko@i.ua

Received: 26.07.2019

Accepted: 30.12.2019

A - Work concept and design, B - Data collection and analysis, C - Responsibility for statistical analysis,

D-Writing the article, $\mathbf{E}$-Critical review, $\mathbf{F}$ - Final approval of the article 